\title{
In Support of Student Academic Success with Technology: The Student View
}

\author{
Prof. Susan L. Miertschin, University of Houston, College of Technology (MERGED MEMBERSHIP WITH \\ COE)
}

Susan L. Miertschin, M.Ed., M.S.I.S., is an Associate Professor teaching in the Computer Information Systems program at University of Houston. Her teaching interests are in the areas of (1) information systems applications development and the complementary nature of back-end developer and front-end developer skill sets and (2) managing IT services. Her research interests are program and student assessment, the impact of instructional technology on student learning, and the improvement of e-learning environments and experiences.

\section{Dr. Barbara Louise Stewart, University of Houston}

Barbara L. Stewart is a Professor of Retailing and Consumer Science at the University of Houston. Her teaching and research interests are in the application of strategies to improve student learning and life enhancement in online courses. She has served as an academic administrator and in leadership positions for numerous professional organizations.

\section{Dr. Carole E. Goodson, University of Houston (CoT)}

Carole Goodson is a Professor of Technology at the University of Houston. As an active member of ASEE, she is a member of the Academy of Fellows, a past Editor of the Journal of Engineering Technology, a past Chair of PIC IV and the ERM Division, and a past Chair of the Gulf Southwest Section of ASEE. 


\section{In Support of Student Academic Success with Technology: The Student View}

\section{Introduction}

In "Digital Natives, Digital Immigrants - Part I," Prensky states that today's students "represent the first generations to grow up with the new technology."'[1] Further, he notes that these students "have spent their entire lives surrounded by and using computers, videogames, digital music players, video cams, cell phones, and all the other toys and tools of the digital age.'[1] Concurrently, course design centering on technology seems to be increasingly central in the education process. The U.S. Department of Education reports that "Used to support both teaching and learning, technology infuses classrooms with digital learning tools, ... course offerings, experiences, and learning materials; ... this technology infusion builds $21^{\text {st }}$ century skills; increases student engagement and motivation; and accelerates learning."'[2]

Increased use of technology by students has expanded opportunities to enhance student success. Today's students are technologically literate as indicated by their ownership and extensive use of technological devices. Based on the 13th annual College Explorer survey administered and analyzed by the marketing agency re:fuel, "Technology is facilitating academic chores."[3] The survey found that college students own, on average, 6.9 technology devices. The PEW Research Center, reports that at least $93 \%$ of college students are home broadband users," compared to the national adult average of 66\%.[4] Furthermore, they note that students own multiple gadgets at high rates as compared with the overall adult population. Specifically, "Undergraduate and graduate students are more likely than both community college students and college-aged nonstudents to own a laptop computer and an iPod or other mp3 player. College students are much more likely than the overall cell phone owner in the population to use the Internet on their mobile phones.'[4]

With all these devices available to them, today's students are interested in appropriate use of technology in their classes. A survey conducted by EDUCAUSE found that college students have "a moderate preference" for technology in the classroom.[5] Additionally, a policy brief from the International Society for Technology in Education proclaims that "In using technology for instruction and learning, students gain more than just knowledge in core subject areas — they also acquire skills necessary to be productive and competitive" in the workplace and other settings.[6]

The authors conducted a survey that addressed technology use in the higher education classroom. Respondents expressed their ideas about how instructors can use technology to support their course success and they answered questions about their technology use. The intent of the current study was to explore the use of technology in the classroom from a student perspective; specifically, how instructors can design and use technology to ensure that it contributes to the students' academic success. Using the results of the survey and related literature, the current study explored and addressed issues such as the following: 
- What course features do students see as important to their success in a class? Does student preference for particular course features vary based on the course format?

- What technologies are preferred in course delivery? Does student preference for technology vary based on the course format?

- How can instructors promote and develop student success through technology and course design features?

Results of the research are presented with implications for course delivery.

\section{Information and Communication Technologies in Higher Education for Learning/Instruction}

It is a fact that students entering college today from high school are digital natives, as defined by Prenksy [1], whereas older students are digital immigrants. It is also a fact that, as information and communication technologies (ICTs) have grown in number and sophistication over the last twenty years, digital tools to support learning and instruction have grown in use and popularity in higher education as well. What is not clear, despite an expansive literature on the topic, is to what extent ICT usage in higher education has improved the learning environment for students and faculty and to what extent student outcomes are being impacted. As ICT use explodes in society, research is being conducted on many fronts regarding the nature, effectiveness, and transformative potential of ICTs in higher education.

\section{Learning Characteristics of Digital Natives}

Some research focuses on the impact of digital native status on the learning characteristics of students, and what implications the changes have for higher education. Learning characteristics have been attributed to digital natives with the claim that they are different from those of digital immigrant students. Included are fluency with digital devices and software, connectedness, high level of multitasking, need for experiential learning, need for immediate feedback/response, social nature that aligns with team work, preference for images over text, and community mindedness.[7, 8] Empirical research has not conclusively verified generational differences with respect to some or all of these learning characteristics. Research by Lai and Hong [7] found statistically significant differences for only four out of ten characteristics they studied. In particular, they found that almost all respondents to their survey felt comfortable using ICTs, regardless of whether they were immigrant or native to the technologies. Kirkwood [9] cites five studies completed since 2008 that failed to support the claim that digital natives exhibit learning characteristics distinct from those of their predecessors. In Bullen, Morgan and Qayyum's review of literature [10], they conclude that most claims in the category of unique behavioral characteristics and learning styles for digital natives are not founded in empirical evidence. Where empirical evidence is reported, it finds no generational differences with respect to many of the listed learning characteristics.[7]

\section{Use of ICTs for Instruction}

Another research area investigates how ICTs are and should be used in higher education instruction. Some pundits look to ICTs for their potential to transform higher education 
instruction from predominately didactic, teacher-centered approaches to student-centered approaches, with student-centered approaches being viewed as the more effective practice in higher education. Research by Englund, Olofsson and Price [11] cites evidence that a studentcentered approach is necessary for effective use of ICTs for instruction. However, a number of studies find that the technologies most frequently employed in instruction in higher education are used to replicate didactic practices whose purpose is to transfer information (content) from instructor to student, which is a teacher-centered approach.[11-13] Kirkwood [9] argues that three factors interact in a complex way to influence when and how technology is used in higher education instruction. The three factors he discusses are the context of learners with content and with teaching and learning strategies; the design for learning which includes types of activities, materials, and resources; and the characteristics and constraints of available technologies.[9] Across the literature, there appears to be a consensus that ICTs have great potential to transform higher education processes in ways that will streamline teaching and learning, making the processes more effective, and thus, benefitting both students and society. However, the same literature recognizes that, to date, ICT use is primarily focused on using technology to replicate existing instructional practices whether or not the practices are proven effective.[9, 13]

Use of ICTs in instruction may be changing over time as familiarity with various technologies grows. In a study of how higher education faculty use ICTs, respondents were asked to list the technologies they had used most in innovative ways for learning. The technology most listed was the learning management system with $24 \%$ listing it, followed by blogging ( $8 \%$ ), and podcasting or recording videos (8\%).[14] Englund, et al. [11] conducted a 10-year longitudinal study that examined whether instructors' approaches to teaching with technology changed over time. They found that some teachers showed no change in their approach to teaching while others moved from a teacher-focused, transmission approach to a more student-focused, facilitative approach. They documented five categories for approaches to teaching and five categories for approaches to teaching with technology. The five approaches to teaching ranged from all teacher-focused activity with the intent of transmitting and transferring information to the students to a studentcentered approach where the teacher attempts to facilitate the student to change his/her conceptions of a topic. The approaches to teaching with technology they identified were somewhat parallel, ranging from teacher-focused activity that uses technology to transmit information about the discipline to students (e.g., recorded lectures) to student-focused activity that uses technology to simulate, for example, real-life decision-making scenarios where the student creates knowledge and understanding through participation in a simulation activity. Their study indicates that student satisfaction with the learning experience is higher when the teacher's approach is more student-focused. They also found evidence of gradual change over time of teacher approaches to using technology from teacher-focused to student focused uses. They concluded that professional development could be useful to move teacher approaches along a continuum of change that would lead to more effective use of ICTs for instruction.[11]

\section{Student Technology Use}

Research has been conducted to investigate how students use technology for learning and for other activities. Miertschin, Stewart \& Goodson [15] focused on mobile versus non-mobile technologies and found that students most frequently used desktops and/or laptops for their academic work, and they used smartphones and tablets more for nonacademic pursuits. A third 
of the students in their study reported not using tablets at all. After the tablet being the device most categorized as not used, the desktop ranked next in that category, with $13 \%$ of the students having reported that they did not use a desktop computer at all. This result was notable since it meant that $13 \%$ of respondents used only mobile devices or laptops, which may indicate a trend toward an affinity for at least portability with respect to devices. A study by Lai \& Hong [7] found that students spent a large amount of time on a limited range of digital technologies which included laptop computers, mobile phones, mp3 players, Internet browsers, a spectrum of Google tools, and Facebook or MySpace. Studies by Brown and Czerniewicz [16] and Thinyane [17] reported that the majority of students in South Africa are exposed to a wide range of digital technologies, in particular mobile phones; however, the use of ICTs for learning was found in these studies to be mostly related to the requirements of courses and focused on course content and learning management systems.

\section{Current Study}

Based on the literature and their personal experience teaching with technology and teaching students who are often eager to use technology in their courses, the authors concluded that continued research regarding student use of technology for learning is warranted. In particular, they focused on the students' perspective of how technologies could help them be successful in their courses. Student perspectives were considered important for investigation because the perceptions students hold influence many behaviors, including behaviors related to learning.

In an attempt to better understand students' perception of the value of certain course features and technologies, the researchers created and disseminated a survey directed at these concepts. The survey was completed by students enrolled in seven university courses in the spring of 2015 . Included in the convenience sample were courses in computer information systems, research methods, merchandising systems, statistics, and supervision. Altogether, two-hundred and fifty six (256) students at the University of Houston were surveyed.

The research aimed to obtain a clearer understanding of answers to the following questions:

- What course features do students see as important to their success in a class? Does student preference for particular course features vary based on the course format?

- What technologies are preferred in course delivery? Does student preference for technology vary based on the course format?

- How can instructors promote and develop student success through technology and course design features'?

\section{Study Procedures}

Students completing the online questionnaire were enrolled in one of seven university courses from somewhat varied disciplines (see Table 1). The format of participating courses included online (2), face-to-face (4), and hybrid courses (1). Courses level included sophomore, junior, senior, and graduate. The learning management system, Blackboard, was used to deliver the questionnaire. In general, Blackboard was the exclusive delivery interface for the online courses and supplemented delivery for the hybrid and face-to-face courses. 
Table 1: Courses Used for Survey Administration

\begin{tabular}{|l|l|l|}
\hline Format & Level & Course Name \\
\hline Face-to-Face & Sophomore & Information Systems Applications \\
\hline Face-to-Face & Junior & Integrated Information Systems \\
\hline Online & Junior & Visual Merchandising \\
\hline Face-to-Face & Senior & Database Admin. \& Implementation \\
\hline Online & Senior & Research Concepts in HDCS \\
\hline Face-to-Face & Senior & Project Management \& Practice \\
\hline Online/Hybrid & Graduate & Data Analysis \\
\hline
\end{tabular}

Questionnaire items were designed to solicit student responses regarding their overall experience with mobile technologies and learning as opposed to their experience in the particular course or course format through which they were administered the survey.

Survey completion was voluntary and students were assured that all responses were anonymous to the instructor as well as in any publication of the results. Student responses were downloaded for analysis with each response record identified by a non-identifying number assigned by the learning management system.

Forty-four items organized into several sections comprised the survey instrument. Section one included these demographic characteristics: 1) student classification (freshman, sophomore, etc.),

2) number of online courses completed, 3) enrollment status (mostly full-time or mostly part-time), 4) age, 5) estimated overall GPA, 6) employment status, 7) gender, 8) major, and 9) course format.

Following the demographic section the survey addressed the following areas:

- preferences for technology features potentially used in classes, explored using semantic differential scale rating of preference for technology features

- preferences for course structural features potentially used in classes, explored using semantic differential scale rating of preference for course features

- approaches/features that instructors could incorporate with technology to better support academic success, explored through open-ended items.

Student responses to the survey items described were tabulated. Tables, graphs, and descriptive measures were used to analyze the data.

\section{Study Results}

\section{Demographics}

Participating students could be characterized as students with experience in online learning in that $66 \%$ of them had completed at least three online courses, and only $7 \%$ had completed no online course. The survey addressed mostly those who were experienced students in that $87 \%$ of 
the students were classified as at least juniors. Most students were under 30 years of age (86\%) and employed, in either a full-time or part-time position (69\%), with a GPA greater than 2.50 (90\%). More of the students who completed the survey attended school mostly full-time (87\%) as opposed to mostly part-time (13\%). Respondents were $48 \%$ women and $51 \%$ men.

\section{Technology Features Used in Class}

In reviewing the data on technology features in the classroom it is interesting to note that in general, students felt more connected to courses that use technology. In responding to the item "I am more actively involved in courses that use technology," $72 \%$ agreed and only $2 \%$ had slight disagreement. In addressing the item "Technology makes me feel more connected with other students," students also indicated agreement with 57\% agreeing and 13\% reporting some degree of disagreement.

The study identified nine features that are frequently found in courses. The students were asked if they would like to see the feature used more (or less) in their classes. These features included: instructor lecture video use, YouTube video use, computer games, computer simulations, student presentations related to course content, e-text content, online collaborative activities, online discussion activities and lecture activities with clickers.

Students were asked to rate their preference for degree of use on a scale that ranged from 0 (I prefer that the feature not be used at all) to 7 (much more). Results were tabulated and are presented in Figure 1. The rankings were based on item means are shown in Table 2.

\section{Table 2: Technology Features Ranked by Preference}

$\begin{array}{lrr}\text { Feature } & \text { Mean } & \text { Rank } \\ \text { Computer Simulations } & 5.04 & 1 \\ \text { You Tube Video Use } & 4.74 & 2 \\ \text { e-text Content } & 4.72 & 2 \\ \text { Instructor Lecture Video Use } & 4.58 & 4 \\ \text { Online Collaborative Activities } & 4.00 & 5 \\ \text { Computer Games } & 3.96 & 5 \\ \text { Student Presentations re Course Content } & 3.93 & 5 \\ \text { Online Discussion Activities } & 3.70 & 8 \\ \text { Lecture Activities with Clickers } & 3.62 & 9\end{array}$


Would you like to see the following course features used more (or less) in classes?

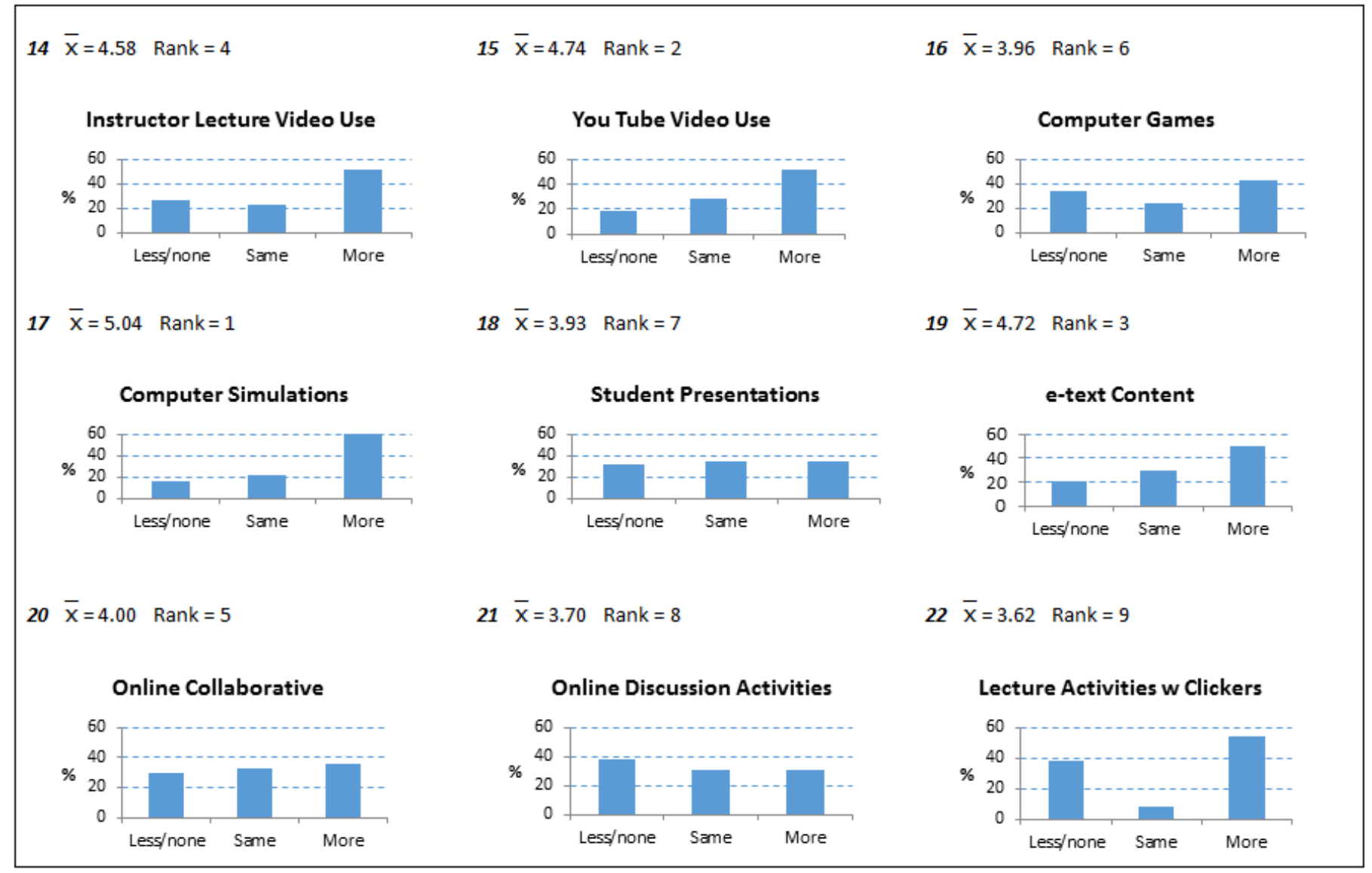

Note: NR data is not reported as less than $0.4 \%$ did not respond to a given item.

\section{Figure 1: Student Preference for Technology Feature}

Indications were that students most frequently felt that computer simulations should be used more in courses. They also had a preference for video content, both content delivered through YouTube and content created by players external to education; for videos of the instructor's lectures; and e-text content. Students were less enthusiastic about use of online collaborative activities, computer games and student presentations related to content. The features that were ranked the lowest were online discussions and lectures that used clickers, with the mean indicating most students felt these features should be used less in courses.

Analysis was completed to determine if a student's cumulative experience with online courses was related to the student preference about each feature. Students responded on the survey that they either took most of their college courses online or they took most of their college courses face-to-face. This factor is considered together with their responses about the value of various course features to their course success. The results are summarized in Table 3 and Figure 2. 
Table 3 Preference for Technology Feature by Course Format

\begin{tabular}{lrrrrrrr} 
& \multicolumn{2}{c}{ Online } & & & \multicolumn{3}{c}{ Face-to-Face } \\
Feature & Less/none & Same & More & Feature & Less/none & Same & More \\
e-text Content & $6 \%$ & $25 \%$ & $67 \%$ & Computer Simulations & $17 \%$ & $20 \%$ & $62 \%$ \\
External Videos & $14 \%$ & $25 \%$ & $61 \%$ & Instructor Video & $26 \%$ & $21 \%$ & $53 \%$ \\
Computer Simulations & $8 \%$ & $33 \%$ & $58 \%$ & External Videos & $20 \%$ & $29 \%$ & $51 \%$ \\
Computer Games & $28 \%$ & $22 \%$ & $50 \%$ & e-text Content & $23 \%$ & $30 \%$ & $47 \%$ \\
Instructor Video & $22 \%$ & $36 \%$ & $42 \%$ & Computer Games & $35 \%$ & $24 \%$ & $41 \%$ \\
Clickers & $25 \%$ & $36 \%$ & $39 \%$ & Collaboration & $30 \%$ & $32 \%$ & $38 \%$ \\
Online Discussion & $22 \%$ & $47 \%$ & $31 \%$ & Online Presentations & $29 \%$ & $35 \%$ & $36 \%$ \\
Collaboration & $36 \%$ & $36 \%$ & $28 \%$ & Clickers & $39 \%$ & $28 \%$ & $33 \%$ \\
Online Presentation & $44 \%$ & $33 \%$ & $22 \%$ & Online Discussion & $41 \%$ & $28 \%$ & $31 \%$
\end{tabular}

\section{Online Ratings of Feature}



Face-to Face Rating of Feature

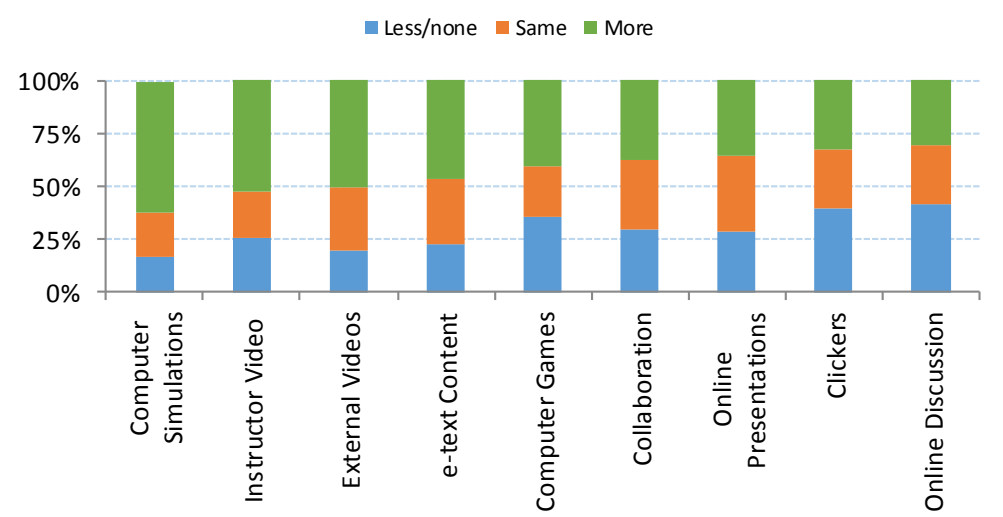

Note: NR data is not reported as less than $0.4 \%$ did not respond to a given item.

Figure 2: Preference for Technology Feature by Course Format 
Students who took courses mostly online had a preference for more external videos, computer games, and e-texts than did those completing most courses face-to-face. Students who completed most courses in a face-to-face format had a greater preference for instructor videos, computer simulations and collaborative activities than did those completing most courses online. None of the students thought that the amount of online student presentations should increase. Most of the students felt that the number of online discussions should be about the same or should decrease.

\section{Course Structural Features}

The study identified five structural features that are found in courses. The students were asked if the feature was important to their success in a course. These features included: prompt response to e-mail by instructor, assignment of grades within a week, student-initiated technology use, instructor-initiated technology use, and contact information for technical support. Students rated the importance of each structural feature on a scale that ranged from 1 (not important) to 7 (very important). Results were tabulated and ranked by mean response, the rankings are shown in Table 4.

\section{Table 4: Importance of Course Structural Features}

$\begin{array}{lrr}\text { How important is the following course feature to your } & & \\ \text { success in class? } & 6.39 & 1 \\ \text { Prompt response to e-mail by instructor } & 6.01 & 2 \\ \text { Assignment grades within a week } & 5.36 & 3 \\ \text { Student-initiated technology use } & 5.36 & 3 \\ \text { Instructor-initiated technology use } & 5.26 & 5 \\ \text { Contact information for technical support } & \end{array}$

Clearly, the students surveyed perceive that communication is paramount for their success in a course. Response to e-mail inquiries was ranked as most important, and timely reporting of grades was also ranked very high in importance.

Using the demographic data collected about number of online courses completed, the importance of these two aspects of communication was examined in the context of how much experience the student had with online courses. This finding of high importance for both aspects continued to hold true for those students completing most courses online as well as those who had completed fewer online courses. The results are displayed in Figure 3 and Figure $3 b$. 


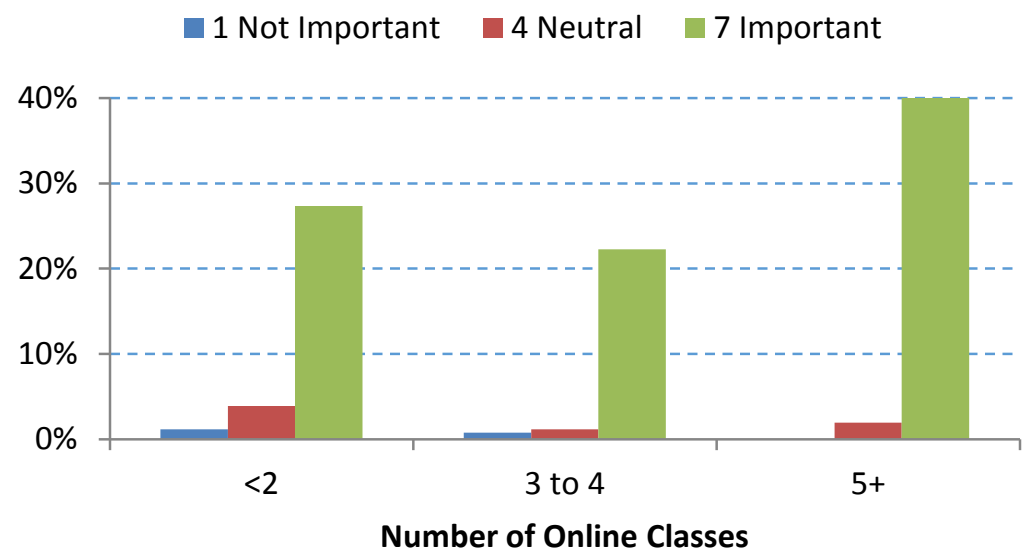

Note: NR data is not reported as less than $0.4 \%$ did not respond to a given item.

Figure 3: Prompt Response to e-mail by Number of OL Courses - Importance to Success

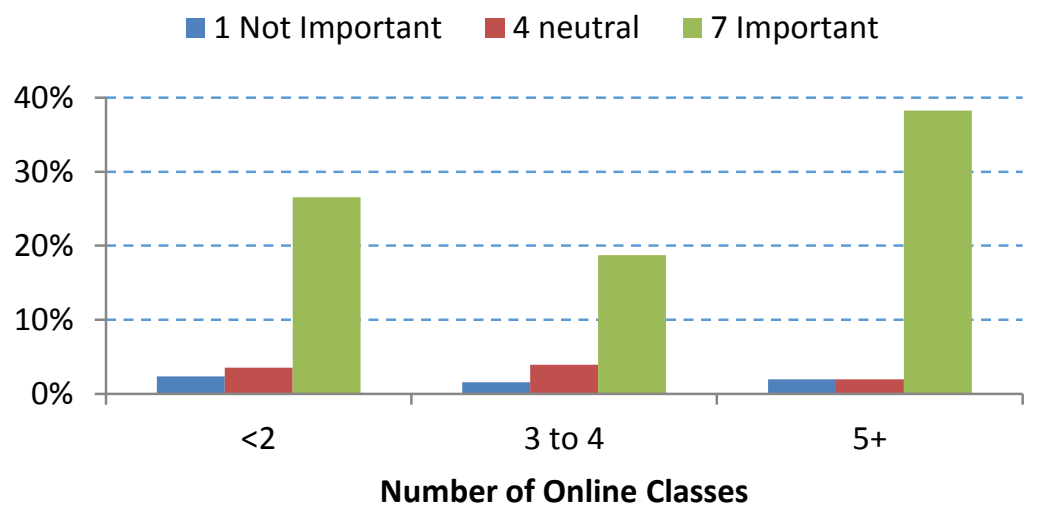

Note: NR data is not reported as less than $0.4 \%$ did not respond to a given item.

Figure 3B: Grade Assignment in One Week by Number of OL Courses - Importance to Success

\section{Role of the Instructor}

Review of the open-ended student responses to survey item number 42 "What can your instructor do with technology to better support your academic success?" provided three useful views of student thought. First, student responses were coded by the researchers to enable categorization of the aspects of technology that students felt instructors could use to enhance instruction. The categories and their ranking by students are shown in Table 5 . The ranking value represents the number of times the concept represented by the category was mentioned in the responses to the open-ended question. Descriptions of each category or examples of items that belong to a category are provided in Table 6 . The descriptions and examples in Table 6 are derived from the student response data. 
Table 5: Ranking of Student Responses to "What can your instructor do with technology to better support your academic success?

\begin{tabular}{lr} 
Category & n \\
\hline Fully online course/content & 56 \\
Scaffolding for technology use & 41 \\
Active learning with technology & 31 \\
Scaffolding for content & 29 \\
Instructor engagement & 18 \\
Accommodate different learning styles & 14 \\
Competent technology use by instructor & 13 \\
Online integration & 12 \\
Content relevant to workplace & 9 \\
Instructor-authored content & 8 \\
Mobile access & 5 \\
Course layout/design & 3 \\
\hline
\end{tabular}


Table 6: Category Descriptions/Examples

Category

Fully online course/content

Scaffolding for technology use

Active learning with technology

Scaffolding for content

Instructor engagement

Accommodate different learning styles

Competent technology use by instructor

Online integration

Content relevant to workplace

Instructor-authored content

Mobile access

Course layout/design

\section{Description/Example}

Provide ALL content online. Essentially, prepare course materials for every course as if it is being offered in an online format.

Provide examples or instruction to help student learn to use the technology needed in the course.

Engage the students with activities that use technology to process, work with, and internalize course content.

Provide examples and other elaborations of course content. Provide more than one content alternative for reaching understanding.

Be engaged with the course and the students through online interactions such as prompt response to student emails. Use social media to create an engaged instructor presence in the course.

Provide videos as well as reading materials. Provide slide presentations and podcasts. Provide alternatives.

The instructor should know how to use the technology present in the course.

Integrate the course content with online content, such as online tutorials and articles.

Prepare materials that demonstrate how the content applies to the workplace.

Use more instructor-authored content such as videos of lectures by the instructor as opposed to videos found on the Web. This was mentioned because instructor prepared content aligns closely with what the instructor expects the students to know for exams and assignments.

Create mechanisms for mobile access to the course.

Create a course layout online that is easy to understand so that it is easy for students to find content items and other course elements and know when things are due.

Second, from the student responses to the open-ended items, a list was created of specific items students reported as a way that faculty could enhance instruction with technology.

Overwhelmingly, the wording used in the open-ended responses fell into the category of "use more of ..." this item. The specific items listed in Table 7, reported in terms the students used, were requested to be used more. The list, organized alphabetically with no attempt to categorize, illustrates how broad is the students' perception and understanding of course elements, features, and technology use for education. 
Table 7: Things to Use More as Stated by Students in Response to "What can your instructor do with technology to better support your academic success?

\begin{tabular}{|c|c|c|}
\hline Item to Use More & Item to Use More & Item to Use More \\
\hline active learning & instructor e-reminders & resources online \\
\hline clickers & interactive online-tutorials & screen sharing \\
\hline collaboration tools & interactive study guides & simulations \\
\hline $\begin{array}{l}\text { content relevant to real job } \\
\text { situations }\end{array}$ & mobile online exams & student engagement \\
\hline demonstrations & objectives for assignments & $\begin{array}{l}\text { student-teacher } \\
\text { communication }\end{array}$ \\
\hline e-books & online content alternatives & support \\
\hline e-contact & online homework & $\begin{array}{l}\text { synchronous online time } \\
\text { with instructor }\end{array}$ \\
\hline e-interaction & online lectures & teacher-led blogs \\
\hline electronic Q\&A forms & online technologies & test solutions \\
\hline examples & online tests & user-friendly technologies \\
\hline free content & online videos & variety of technologies \\
\hline guided hands-on work & resource apps & \\
\hline
\end{tabular}

In addition to these items suggested by students as desirable for courses, students reported that instructors could use technology more effectively by the following practices: complementing students' use of technology by using it themselves, using the newest technologies, responding to student questions faster, providing evaluations more quickly, and organizing online content better. Clearly, students saw many opportunities to enhance their success via instructor use of technology.

Third, student responses were recoded to examine broad categories of opportunities for instructors to support academic success. The categories that emerged were related to communication, subject matter immersion, and provision of examples and demonstrations.

Regarding communication, students suggested that instructors could use technology to reply to student inquiries and return grades more quickly. Mobile technology specifically was cited as a means to communicate with class members since students tend to always be on their mobile devices. Students also thought that frequent emails from professors could make classes seem more real as well as serve as reminders of class assignments. Students even suggested that they would benefit if faculty members would blog about course content. Collaboration was an aspect that students valued and that they felt could be enhanced through the use of technology. Collaboration tools such as Google Hangouts or Prezi for group presentation development, as well as screen-share technologies and online discussions were specifically mentioned. 
For immersion, students wanted technology use to enable them to engage more fully with the course content. Suggestions made included interesting and effective course activities, activities involving group interactions, interactive use of mobile devices and clickers, faculty interaction with students via technology, simulations, and interactive tutorials. Closely related to students' desire to use technology to engage them in the content were their requests for content examples and demonstrations. Hands-on experiences were seen as a visual way for the instructor to know what students do and do not understand. Demonstrating content and showing step-by-step processes, as well as incorporating videos of such were desired. Students reported that videos would make learning easier and more fun. YouTube videos related to the coursework were seen as a means to facilitate comprehension of information from a different perspective. An interesting request from students was for examples and videos of the work of previous students. Another aspect of some suggestions related to the precision with which content presentation mapped to assessments. Students do not want more content for content's sake; they want it to be content focused on the knowledge and skills that will be assessed in the course.

Finally, in addition to the three categories described above (communication, immersion, and examples/demonstrations) student commented on the need for instructors to be competent in and to use the latest technologies and devices and then, when requiring students to use a specific technology, to demonstrate it and allow students to have hands-on practice applying it.

\section{Discussion}

Student responses showed great value for the use of technology to support academic success. This merits strong consideration by instructors and course designers. These findings support and extend the view shared by Prensky [1] and others [2-6] that not only have today's students been surrounded by technology tools and toys their entire lives, but they also value the use of these tools (and toys) in learning.

\section{Preferences for technology features used in classes}

The finding that students felt more connected to courses that use technology not only encourages their use in the design of curriculum, but also corroborates the findings of the U.S. Department of Education that technology infused classrooms increase student engagement and motivation, and thus, accelerate learning.[2] The ranking of the nine technology features in this study provides clarification and direction for which technologies to infuse. Most frequently preferred were computer simulations, YouTube and instructor-created videos, and e-texts. These can easily be incorporated into course design as engagement-creating means to deliver content. It is interesting to note than students with greater online course experience preferred these features at a higher rate than students with less online experience. This suggests that experiencing these or other online tools may lead to greater appreciation for these uses of technology.

\section{Importance of Course Structural Features}

From examination of the findings related to the course structural features we learn that students value technology use for the way it interacts and facilitates the structural features that contribute 
to course success. Not surprisingly, communication was reported as most highly valued and, indeed, some element of communication captured the first, second and fifth ranked positions. Students appreciated promptness in both instructor responses to student e-mails (ranked 1) and assignment grades (ranked 2). They also appreciated contact information for technical support (ranked 5). This shows that they need immediacy in feedback from the instructor for questions and inquiries and for progress in the course. In addition they need technical support. It is interesting to note that these findings were consistent among students regardless of their levels of experience with online and face-to-face course formats. We might conclude that these are generally universal needs for all students, and thus, issues of prompt communication and feedback may merit solid attention from course designers and faculty members.

\section{Value for instructor roles related to technology}

Overwhelmingly student responses to the question "What can your instructor do with technology to better support your academic success?" requested more use of technology. This reflects a positive outlook for the use of technologies to increase learning. Because students saw great opportunities to enhance their success via instructor use of technology, from the findings reported in this study, educators can apply a substantial list of technology uses that are valued by students. Specifically, the findings provide recommendations for approaches to greater use of technology in three categories: communication, subject matter immersion, and examples/demonstrations. For communication, speedy response to student inquiries and return of graded work, use of mobile technology to facilitate communication with and among students, use of frequent e-mails to make classes seem more real and remind students of assignments, a faculty blog, and application of collaboration tools all offer opportunities to propel student success. For immersion, students recommended enticing course activities, group interactions, interactive use of mobile devices and clickers, simulations, and interactive tutorials as means to enable them to engage more fully with course content. These can be applied to future course design. Students' desires for content demonstrations and examples are an additional design aspect that can be included in course creation planning. Allowing students to have hands-on experiences, showing step-by-step processes, sharing videos (including YouTube videos), and examples of previous student work were also viewed by students as ways to support their learning experience. All of these are readily available to instructors to incorporate into their courses.

\section{Conclusions and Recommendations}

In sum, students in this study valued the use of technology in their learning endeavors. They found some applications more useful than others and, in general, proposed the use of more technology to facilitate their success. Wise faculty members and instructional designers can use these findings to examine and apply the specific technology and course structural features presented here. Further, the recommendations made by students for instructors and the descriptions of technologies for which they requested greater use is instructive for course design and execution.

Future investigations may be beneficial to share the application of these findings. While the use of technology at the university in the study is likely similar to that of other institutions, no assumptions for other applications should be made without further investigation. Case studies 
illuminating the benefits and challenges of using the tools and concepts will be useful. Additionally, investigation is merited not only on student perceptions of how their instructors can enhance technology use, but also how colleges and universities as well as students themselves can use technology to fuel their academic success. Collecting empirical evidence of improvement in student engagement through the use of technology would also be valuable.

\section{List of References}

1. Prensky, M., Digital natives, digital immigrants, part I. On the Horizon, 2001. 9(5).

2. U.S. Department of Education, Use of Technology in Teaching and Learning. [cited 01 Oct 2016]; Available from: https://www.ed.gov/oii-news/use-technology-teaching-and-learning.

3. re:fuel, Tech-savvy college students are gathering gadgets, saying yes to showrooming and rejecting second-screening. [cited 01 Oct 2016]; Available from: http://www.globenewswire.com/news-release/2013/06/13/554002/10036312/en/Tech-SavvyCollege-Students-Are-Gathering-Gadgets-Saying-Yes-to-Showrooming-and-Rejecting-SecondScreening.html. 2013.

4. Smith, A., L. Rainie, and K. Zickuhr, College Students and Technology. [cite 01 Oct 2016], Available from: http://www.pewinternet.org/2011/07/19/college-students-and-technology/. 2011.

5. Kvavki, R.B., Convenience, communications, and control: How students use technology in the classroom, in Educating the Net Generation, D.G. Oblinger and J.L. Obliner, Editors. 2005, EDUCAUSE.

6. Technology and Student Achievement: The Indelible Link. 2008, International Society for Technology in Education (ISTE).

7. Lai, K.-W. and K.-S. Hong, Technology use and learning characteristics of students in higher education: Do generational differences exist? British Journal of Educational Technology, 2015. 46(4): p. 725-738.

8. Thompson, P., The digital natives as learners: Technology use patterns and approaches to learning. Computers \& Education, 2013. 65: p. 12-33.

9. Kirkwood, A., Teaching and learning with technology in higher education: blended and distance education needs 'joined-up thinking' rather than technological determinism. Open Learning, 2014. 29(3): p. 206-221.

10. Bullen, M., T. Morgan, and A. Qayyum, Digital Learners in Higher Education: Generation is Not the Issue. Apprenants numériques en enseignement supérieur: la génération n'est pas en cause, 2011. 37(1): p. 1-24.

11. Englund, C., A.D. Olofsson, and L. Price, Teaching with technology in higher education: understanding conceptual change and development in practice. Higher Education Research \& Development, 2017. 36(1): p. 73-87.

12. Daniel, J. Making sense of MOOCs: Musings in a maze of myth, paradox and possibility. [cited 12 Dec 2016]; Available from: http://sirjohn.ca/wordpress/wp-content/uploads/2012/08/MOOCsBest.pdf. 2012.

13. Kirkwood, A. and L. Price, Technology-enhanced learning and teaching in higher education: what is 'enhanced' and how do we know? A critical literature review. Learning, Media and Technology, 2014. 39(1): p. 6-36.

14. Ng'ambi, D., Effective and ineffective uses of emerging technologies: Towards a transformative pedagogical model. British Journal of Educational Technology, 2013. 44(4): p. 652-661.

15. Miertschin, S.L., B.L. Stewart, and C.E. Goodon, Mobile devices and lifelong learning: The students' perspective. Computers in Education, 2017. In press. 
16. Brown, C. and L. Czerniewicz. Trends in student use of ICTs in higher education in Sourth Africa. in Proceedings of the 10th Annual Conference of WWW Applications. 2008. Capetown, SA: Cape University of Technology.

17. Thinyane, H., Are digital natives a world-wide phenomenon? An investigation into South African first year students' use and experience with technology. Computers \& Education, 2010. 55(1): p. 406-414. 